\title{
Hydrothermal degradation of $\beta$-estradiol and oxytetracycline at selective reaction severities
}

\author{
Nepu Saha ${ }^{1} \cdot$ Kyle McGaughy ${ }^{1} \cdot$ Michael A. Held $^{2} \cdot$ M. Toufiq Reza ${ }^{1}$ (D)
}

Received: 29 January 2020 / Accepted: 26 August 2020 / Published online: 31 August 2020

(c) Springer Nature Switzerland AG 2020

\begin{abstract}
Hydrothermal carbonization (HTC) is a thermochemical process that produces biofuels and carbon-based materials from wastes; the solid product is commonly known as hydrochar. However, the fate of common pharmaceutical products during HTC has not been explored extensively. Knowledge on degradation pathways for emerging contaminants is important for further application of hydrochar, especially for water purification and soil amendment. Therefore, the objective of this study was to investigate the degradation of two emerging pollutants (i.e., oxytetracycline and $17 \beta$-estradiol) with HTC temperature, residence time, and initial chemical states. High-performance liquid chromatography and gas chromatography-mass spectroscopy (GCMS) were used to analyze the levels of degradation of oxytetracycline and $\beta$-estradiol and the secondary products generated due to their primary degradations, respectively. The results showed that the degradation of oxytetracycline and $\beta$-estradiol did not depend significantly on the HTC temperature and residence time. However, their degradation depends significantly on the initial $\mathrm{pH}$ of the solution. The maximum degradation of oxytetracycline and $\beta$-estradiol was observed at $84.1 \pm 2.9 \%$ and $100 \%$ at initial $\mathrm{pH} 8$ and $\mathrm{pH} 3$, respectively. GCMS results showed that stable acidic compounds (such as benzoic acid and furoic acids) were produced due to the degradation of both oxytetracycline and $\beta$-estradiol in most of the experimental conditions.
\end{abstract}

Graphic abstract Synopsis: Degradation of both oxytetracycline and $\beta$-estradiol mainly produced benzoic acid and other functionalized monocyclic aromatics

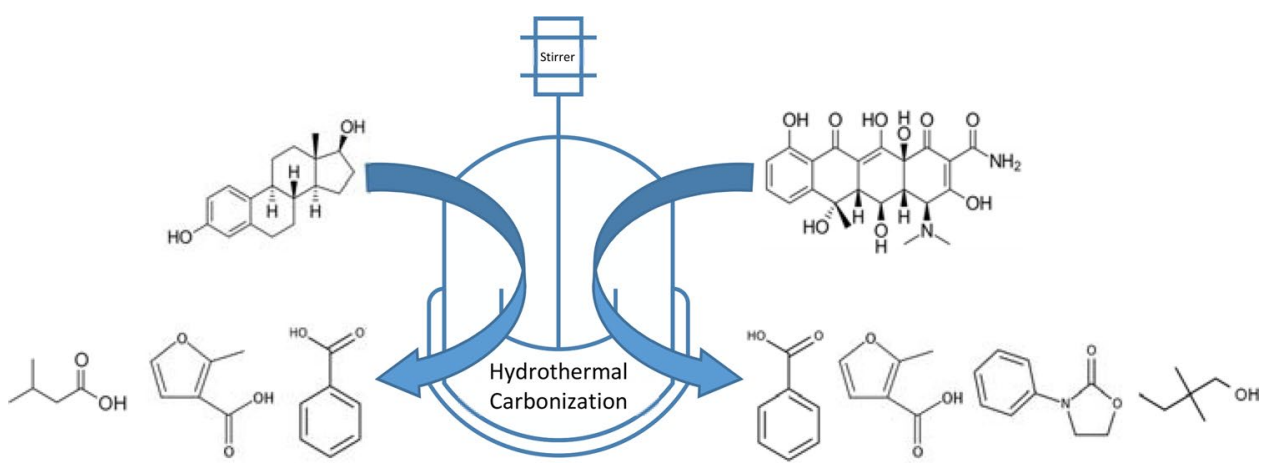

Electronic supplementary material The online version of this article (https://doi.org/10.1007/s42452-020-03436-0) contains supplementary material, which is available to authorized users.

$\triangle$ M. Toufiq Reza, treza@fit.edu| ${ }^{1}$ Department of Biomedical and Chemical Engineering and Sciences, Florida Institute of Technology, 150 W University Blvd, Melbourne FL 32901, USA. ${ }^{2}$ Department of Chemistry and Biochemistry, Biochemistry Research Facility, Ohio University, 350 W State St, Athens OH 45701, USA. 
Keywords Hydrothermal carbonization · Emerging pollutants $\cdot$ Oxytetracycline $\cdot 17 \beta$-estradiol

\section{Introduction}

Hydrothermal carbonization (HTC) is a promising thermochemical process that converts wet biomass like animal manures into solid fuel and functionalized materials by using high temperatures and saturated vapor pressures [1-3]. Traditionally, lignocellulosic biomasses have been mainly used as a feedstock for HTC to produce solid fuel with properties similar to lignite coal [4]. In the last few years, however, HTC technology has been used for numerous non-lignocellulosic biowastes [5, 6]. Two major advantages that can be attributed to HTC of biowastes include (a) remediation of wastes and (b) synthesis of value-added products [2]. Due to the low fuel quality of waste-derived hydrochars compared to coal, alternative applications of hydrochars have been explored (i.e., hydrochars used as adsorbent, filter media, fertilizer) [1, 7-10]. Unlike lignocellulosic biomass, biowastes like manure, sewage sludge, and septage often contain emerging pollutants including hormones and antibiotics. In fact, more than $3300 \pm 700 \mathrm{ng} / \mathrm{L}$ of estradiol and $290 \pm 50 \mathrm{ng} / \mathrm{L}$ of neomycin were reported in the runoff from farmland amended with dairy manure $[11,12]$. Hormones are biologically active at very low levels and may disrupt the reproductive endocrinology of fish, while antibiotics facilitate the development and proliferation of antibiotic resistance bacteria [13]. Therefore, both hormones and antibiotics are considered as emerging pollutants for the environment and need to be prevented from reaching food and water sources. HTC has already been proven to carbonize these waste materials that may contain hormones and antibiotics; however, in order to apply hydrochar as adsorbent, filter media, or fertilizer, the fate of these contaminants needs to be studied $[14,15]$.

The solvent properties of water at ambient conditions are drastically different compared to the properties at subcritical conditions [16]. The dielectric constant of water decreases, and the water dissociation constant increases with increasing temperature. As a result, subcritical water around $160-280^{\circ} \mathrm{C}$ shows more significant self-dissociation into $\mathrm{H}^{+}$and $\mathrm{OH}^{-}$and is also influenced by the strong clustering effect [17]. This leads to a high "local concentration" of $\mathrm{H}^{+}$and $\mathrm{OH}^{-}$ions. As a result, a hydrogen atom of water comes very near to a reactive center of an organic molecule. Most hormones and antibiotics (i.e., oxytetracycline, $\beta$-estradiol, etc.) contain saturated and unsaturated $\mathrm{C}-\mathrm{C}$ bonds, as well as ketones, hydroxyls, and amines. Thus, individual compounds participate in different types of reactions (e.g., hydrolysis, nucleophilic substitution, deprotonation, etc.) and degrade differently at different rates in subcritical conditions [18].

As of now, few studies have been conducted to investigate the degradation of pharmaceutical products at HTC conditions. Weiner et al. [19] investigated the influence of HTC temperature and residence time on the degradation of organic pollutants (i.e., ibuprofen, diclofenac, tetrabutyltin, etc.). They observed that each pollutant degraded differently at different HTC conditions and some of them formed stable intermediates (mainly functionalized phenolic compounds) which cannot further degrade at that HTC condition. Recently, Eyser et al. [20] studied the removal efficiency of pharmaceuticals (i.e., diclofenac, ibuprofen, phenazone, carbamazepine, etc.) from sewage sludge during $\mathrm{HTC}$ at a single condition (temperature: $210^{\circ} \mathrm{C}$ and residence time: $4 \mathrm{~h}$ ). They found that most compounds were degraded or at least reduced from their initial concentration, after HTC. Other methods using hydrothermal treatment as part of a treatment process have shown success as well in removing hormones from waste streams. A combined treatment method using algae and hydrothermal treatment was performed by Shin et al. [21] in order to remove several estrogenic compounds from swine manure. Results reported are promising, with more than $75 \%$ of all examined estrogenic compounds being removed in the final product phase. Concentrated oxytetracycline residue was treated hydrothermally by Gong et al. [22] who reported near full removal of the common antibiotic with hydrothermal conditions of $180^{\circ} \mathrm{C}$ and $120 \mathrm{~min}$. However, this residue is extremely concentrated, while the levels of antibiotics and hormones found in dairy wastes are typically very low $[23,24]$.

Currently, six steroids and more than 50 antibiotics are approved by the Food and Drug Administration (FDA) for use in feed animals [25]. The hormones are estradiol, progesterone, testosterone, trenbolone acetate, progestin melengestrol acetate, and zeranol, where the common antibiotics are roxithromycin, sarafloxacin, virginiamycin, oxytetracycline, and neomycin $[25,26]$. Although it is clear from the literature that HTC can degrade some micro-pollutants/pharmaceuticals, the HTC degradation of common antibiotics and hormones as they are found on dairy farms (e.g., low concentration and in the presence of other compounds) has not been investigated.

Therefore, the objective of this study is to investigate the degradation phenomenon of emerging pollutants of dairy manure with respect to HTC process conditions such as temperature, residence time, and initial $\mathrm{pH}$ and to then develop following a proposed degradation mechanism based on the degradation products found. In order to 
understand the phenomenon, a series of HTC experiments were conducted at different temperatures, residence time, $\mathrm{pH}$, and in the presence of glucose by using two model compounds (oxytetracycline and $\beta$-estradiol). Oxytetracycline and $\beta$-estradiol were chosen for this study because they are the most commonly used hormone and antibiotics on dairy farms. Since these compounds are not found in isolation, additional experiments with glucose (a common HTC feedstock) were included to examine how oxytetracycline and $\beta$-estradiol degradation behavior may change in isolation compared to degradation in the presence of other compounds. High-performance liquid chromatography (HPLC) and gas chromatography coupled with a mass spectrometer (GCMS) were used to analyze the presence of unreacted pollutants and degraded products in process liquid, respectively.

\section{Materials and methods}

\subsection{Materials}

Oxytetracycline and $17 \beta$-estradiol (referred to as $\beta$-estradiol) were purchased from Sigma-Aldrich (St. Louis, MO) for HTC experiments. $\mathrm{HCl}(0.01 \mathrm{M})$ and $\mathrm{NaOH}$ $(0.01 \mathrm{M})$ were purchased from Fisher Scientific to prepare the samples with defined $\mathrm{pH}$. High-performance liquid chromatography (HPLC)-grade acetonitrile (ACN) and trifluoroacetic acid (TFA) were procured from Fisher Scientific (Hanover Park, IL) for HPLC. In addition, pyridine, bistrifluoroacetamide (BSFTA) with trimethylsilyl chloride (TMSC) (99:1), and dichloromethane (DCM) were procured from Sigma-Aldrich (St. Louis, MO) for derivatization of the HTC products.

\subsection{Methods}

\subsubsection{Sample preparation}

Pure oxytetracycline and $\beta$-estradiol were dissolved in DI water to prepare the corresponding stock solutions. The solubilities of oxytetracycline and $\beta$-estradiol in DI water are $13 \mathrm{mg} / \mathrm{L}$ at $25^{\circ} \mathrm{C}$ and $3.6 \mathrm{mg} / \mathrm{L}$ at $27^{\circ} \mathrm{C}$, respectively [27]. The stock solution of oxytetracycline was prepared at the same concentration of its water solubility as the highest concentration of oxytetracycline in cow manure was observed $13.77 \mathrm{mg} / \mathrm{kg}$ [23]. Although the solubility of $\beta$-estradiol is $3.6 \mathrm{mg} / \mathrm{L}$, a stock solution was prepared as a concentration of $110 \mu \mathrm{g} / \mathrm{L}$ because the presence of $\beta$-estradiol in manure is approximately $110 \mu \mathrm{g} / \mathrm{L}$ [24]. Initial $\mathrm{pH}$ of the solution was controlled by adding $0.01 \mathrm{M} \mathrm{HCl}$ or $0.01 \mathrm{M} \mathrm{NaOH}$.

\subsubsection{Experimental methods}

A $100 \mathrm{~mL}$ Parr reactor (reactor series 2430, Moline, IL) was used to perform the HTC experiments. A Parr proportional-integral-derivative (PID) controller (Model 4848) with an accuracy of $\pm 3^{\circ} \mathrm{C}$ was used to control the reaction temperature. The pressure was not controlled but was monitored during the HTC reaction with a pressure gauge. The reactor was filled with $45 \mathrm{ml}$ of the stock solution for each experiment. The HTC experiments were conducted at five different temperatures $(180,220,260,280$, and $\left.300^{\circ} \mathrm{C}\right)$, two different residence times $(0.5$ and $6.0 \mathrm{~h})$, and five different $\mathrm{pH}(3,4,7,8$, and 10) to investigate the effects of HTC temperature, residence time, and acidity/ alkalinity on the degradation of $\beta$-estradiol and oxytetracycline individually. In addition, $2 \mathrm{~g}$ of glucose was added to select experiments to investigate its effect on the degradation of $\beta$-estradiol and oxytetracycline. The initial $\mathrm{pH}$ of these glucose-containing solutions was 3.65. A detailed experimental matrix is shown in Table 1 . The reactor was heated at a constant rate of $10^{\circ} \mathrm{C} / \mathrm{min}$ until it reached the desired temperature and then held at that temperature for either 0.5 or $6 \mathrm{~h}$. At the end of the HTC reaction time, the heater was turned off, and the reactor was rapidly cooled to room temperature $\left(\sim 30^{\circ} \mathrm{C}\right)$ by placing it in an ice-water bath. Solid products were filtered using Whatman 41 filter paper, and around $10 \mathrm{ml}$ of process liquid was collected and refrigerated in a glass vial for further analyses. All experiments were completed in triplicate.

\subsubsection{Characterization of HTC process liquid}

HTC process liquid samples were analyzed using Agilent 1100 series HPLC instrument (Santa Clara, CA) fitted with

Table 1 Detailed experimental matrix of hydrothermal degradation of $\beta$-estradiol and oxytetracycline at various HTC conditions

\begin{tabular}{llll}
\hline Sample & $\begin{array}{l}\text { Residence } \\
\text { time }(\mathrm{hr})\end{array}$ & $\begin{array}{l}\mathrm{HTC} \text { tem- } \\
\text { perature }\left({ }^{\circ} \mathrm{C}\right)\end{array}$ & $\mathrm{pH}$ \\
\hline$\beta$-estradiol & 0.5 & 180 & $\mathrm{~N}^{*}$ \\
& 0.5 & 220 & $3,4, \mathrm{~N}^{*}, 8,10, \mathrm{POG}^{\#}$ \\
& 0.5 & 260 & $\mathrm{~N}^{*}$ \\
& 0.5 & 280 & $\mathrm{~N}^{*}$ \\
& 0.5 & 300 & $\mathrm{~N}^{*}$ \\
Oxytetracycline & 6.0 & 220 & $\mathrm{~N}^{*}$ \\
& 0.5 & 180 & $\mathrm{~N}^{*}$ \\
& 0.5 & 220 & $3,4, \mathrm{~N}^{*}, 8,10, \mathrm{POG}^{\#}$ \\
& 0.5 & 260 & $\mathrm{~N}^{*}$ \\
& 0.5 & 280 & $\mathrm{~N}^{*}$ \\
& 0.5 & 300 & $\mathrm{~N}^{*}$ \\
& 6.0 & 220 & $\mathrm{~N}^{*}$ \\
\hline
\end{tabular}

${ }^{*} \mathrm{~N}=$ neutral $\mathrm{pH},{ }^{\#} \mathrm{POG}=$ presence of glucose 
a Bio-Sil C18 HL 90-3 S (150 mm × 4.6 mm, Ref. 615-0250). Samples $(20 \mu \mathrm{L})$ were loaded onto the column equilibrated with $39.6 \%$ acetonitrile in $0.1 \%(\mathrm{v} / \mathrm{v})$ trifluoroacetic acid (aq). Elution proceeded isocratically for $1 \mathrm{~min}$ followed by a linear gradient to $90 \%(\mathrm{v} / \mathrm{v})$ acetonitrile in $0.1 \%$ trifluoroacetic acid (aq) over $14 \mathrm{~min}$. Flow rates were set at $0.4 \mathrm{~mL} / \mathrm{min}$ for all samples. The column was re-equilibrated for 10 min between each injection. Oxytetracycline was detected using an in-line fluorescence detector with excitation and emission wavelengths of $280 \mathrm{~nm}$ and $310 \mathrm{~nm}$, respectively. Similarly, $\beta$-estradiol was detected using an in-line ultraviolet (UV) detector at an absorbance wavelength of $235 \mathrm{~nm}$. Peak areas of known concentrations of oxytetracycline and $\beta$-estradiol standards were integrated to generate calibration curves. The lower limit of detection (LOD) of oxytetracycline and $\beta$-estradiol was observed to be 80 and $22 \mu \mathrm{g} / \mathrm{L}$, respectively. Additionally, for non-HPLC characterization, UV-Vis was performed using a Hach DR/6000 spectrophotometer. This was used to analyze oxytetracycline degradation before and after HTC treatment by measuring a shift in peak absorbance wavelength. A sample of oxytetracycline was prepared at $1 \mu \mathrm{g} / \mathrm{L}$ and compared to a similar sample that had been treated. Samples were serially diluted to ensure that peak absorbance wavelength was concentration dependent.

GCMS was used for the identification of unknown components produced in the HTC reaction. The silylation derivatization of the polar components was performed to qualitatively identify unknown components. For silylation derivatization, liquid samples $(125 \mu \mathrm{L})$ were freeze-dried in deactivated $1.5 \mathrm{~mL}$ vials. ACN $(100 \mu \mathrm{L})$ was added to dissolve the dried solids. Then, pyridine $(50 \mu \mathrm{L})$ and BSFTA with TMCS (99:1) $(100 \mu \mathrm{L})$ were added into the vials. The capped vials were placed in a water bath for $2 \mathrm{~h}$ to allow complete silylation. The temperature of the water bath was maintained at $65{ }^{\circ} \mathrm{C}$. After silylation, the samples were cooled to room temperature and an aliquot $(100 \mu \mathrm{L})$ was collected and diluted with dichloromethane (1.4 mL).
Samples were injected into a Shimadzu GCMS-QP2010S instrument (Chicago, IL) equipped with Shimadzu SHR5XLB column $(30 \mathrm{~m} \times 0.25 \mathrm{~mm} I D, 0.25 \mu \mathrm{m}$ film thickness) and electron ionization (EI) mass detector. The electron ionization is the ionization technique used to form ions (and fragments) which then will be separated according to their mass-per-charge ratio $(\mathrm{m} / \mathrm{z})$ in a mass analyzer and detected. The column temperature was maintained at $80^{\circ} \mathrm{C}$ for $2 \mathrm{~min}$, then increased to $260^{\circ} \mathrm{C}$ at a rate of $10^{\circ} \mathrm{C} /$ $\mathrm{min}$, and then kept there for $2 \mathrm{~min}$.

\section{Results and discussion}

\subsection{Degradation of $\beta$-estradiol at different HTC conditions}

$\beta$-estradiol is a steroid hormone which has two hydroxyl groups: one at the $C 3$ position and another at the $17 \beta$ position. $\beta$-estradiol was able to be partially degraded by the HTC process, with specific results shown in Fig. 1. Generally, increasing HTC temperature, time, and either alkalinity or acidity increased the amount of degradation. Figure 1 shows that the degradation of $\beta$-estradiol was $29.7 \pm 2.1 \%$ at $180^{\circ} \mathrm{C}$. This value increased gradually with increasing HTC temperature from 180 to $260^{\circ} \mathrm{C}$, with $48.5 \pm 2.5 \%$ degradation at $300^{\circ} \mathrm{C}$ (both trials were for $0.5 \mathrm{~h}$ at neutral $\mathrm{pH}$ ). Increasing the treatment time, while at $220^{\circ} \mathrm{C}$ and neutral $\mathrm{pH}$, increased the degradation (from $37.6 \pm 6.0 \%$ at $0.5 \mathrm{~h}$ to $53.6 \pm 2.0 \%$ at $6.0 \mathrm{~h}$ ) but still did not fully remove the $\beta$-estradiol. Changing $\mathrm{pH}$ had a more significant impact on degradation, as Fig. 1 shows that the degradation of $\beta$-estradiol treated at neutral conditions for $30 \mathrm{~min}$ at $220^{\circ} \mathrm{C}$ was $37.6 \pm 6.0 \%$ and further increased to $58.6 \pm 0.4 \%$ and $100 \%$ at $\mathrm{pH}$ of 10 and $\mathrm{pH}$ of 3 , respectively.

It is also valuable to know what compounds are being formed from the degradation of the $\beta$-estradiol. The GCMS data show consistently that the same compounds were
Figure. 1 Percentage of degradation of $\beta$-estradiol at different HTC conditions with and without the presence of glucose. The parent concentration of $\beta$-estradiol was $110 \mu \mathrm{g} / \mathrm{L}$

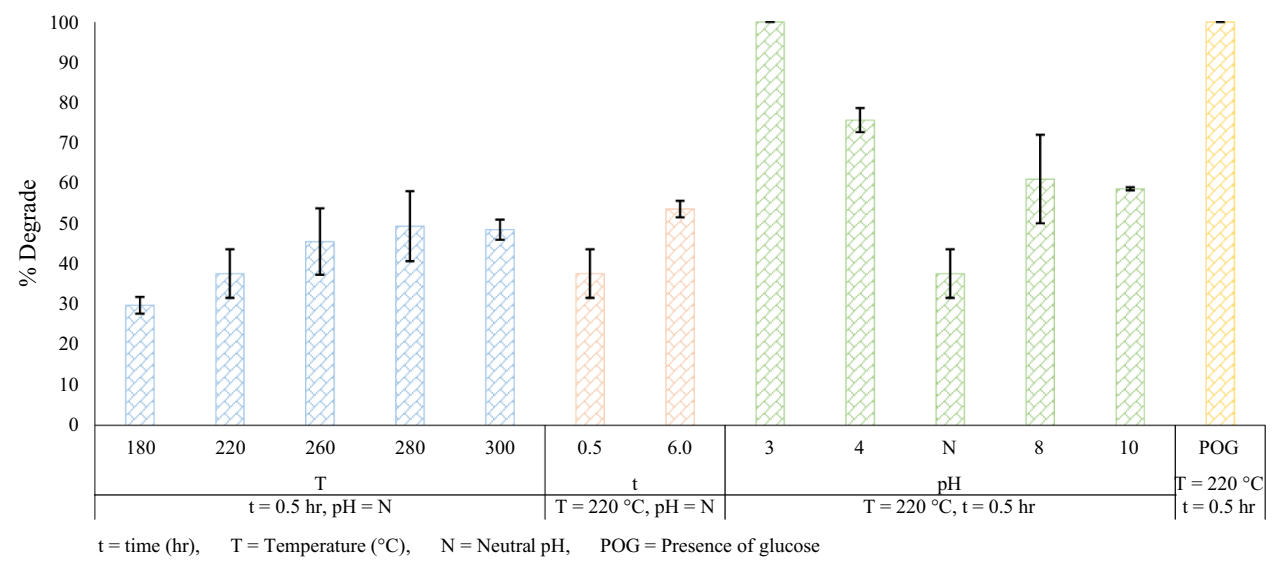


formed regardless of temperature, time, or $\mathrm{pH}$ of treatment. For all $\beta$-estradiol trials, fragment ions were found at $\mathrm{m} / \mathrm{z} 44,77,105,135$, and 179 . This is an $82 \%$ match for benzoic acid that has been functionalized by a trimethylsilyl ester (formed as a result of the derivatization process). 2-methyl 3-furoic acid (with a 75\% match), 3-methyl-butanoic acid (with a $75 \%$ match), and glucose (with a $95 \%$ match) were also found as minor products in the product liquid for all experiments involving $\beta$-estradiol. This profile was found regardless of treatment conditions, which is significant as this suggests that the initial products formed are stable and will not degrade further. McCollom et al. [28] have hypothesized that the degradation of toluene to benzene under hydrothermal conditions with metal catalysts goes through a benzoic acid step. Since this study did not evaluate metal catalysts, it is expected that any monocyclic aromatic degradation products would still be found after treatment. No benzene was found in any of the samples prepared in this study, suggesting that the monocyclic aromatics that form from the ring breaking mechanism are stable. This is in agreement with an earlier study that found monocyclic aromatics are stable even at conditions that exceed those explored in this study [29]. The ring cleavage of $\beta$-estradiol could be responsible for forming benzoic acid, rather than the combination of smaller fragments into an aromatic ring. Given that 2-methyl 3-furoic acid is found in all samples, while there is no initial furoic oxygen in $\beta$-estradiol, fragmentation and subsequent hydrolysis/oxidation must be occurring during the degradation process as well.

Changing the $\mathrm{pH}$ had a more significant effect on the degradation of $\beta$-estradiol compared to HTC temperature or reaction time. This indicates that the degradation of $\beta$-estradiol proceeds via an acid-/base-catalyzed reaction. Since additional oxidizing or reducing agents were not added, it is expected that there would be a variety of short-chained carboxylic acids in the product phase due to the hydrolysis of the fragmentation products that result from the ring opening degradation of the $\beta$-estradiol. This is exactly what was found with the detection of both 2-methyl 3-furoic acid and 3-methyl-butanoic acid [30, 31]. Onwudili et al. demonstrated in their study on oxidative degradation of phenanthrene that benzoic acid and other oxygen-containing aromatics are stable under hydrothermal conditions even when paired with aliphatic oxygenates [32]. These studies, when paired with the characterization of the degradation products, show that the non-aromatic portions of $\beta$-estradiol are the weakest points that should be targeted to promote degradation. Furthermore, trials with non-neutral $\mathrm{pH}$ show that baseand acid-catalyzed reactions are the most likely pathway for $\beta$-estradiol degradation. The glucose additive trial demonstrates that additional fragments are able to attack the same sites and further enhance degradation. As previously mentioned, the literature supports that oxygenated aliphatics alone are not enough to break down the benzoic acid products [32]. The addition of glucose has a significant impact on the stability of $\beta$-estradiol. At the end of treatment, there was no $\beta$-estradiol remaining. Glucose is known to form furan derivatives (as well as a fair amount of acids) such as hydroxymethyl furfural and furfural when hydrothermally treated by itself [33]. These intermediates (see Table S1) may facilitate ring opening mechanisms previously discussed and result in total degradation of $\beta$-estradiol. The GCMS profile suggests additional carboxylic acid formation with the detection of both acetic acid (89\% match) and pentatonic acid (93\% match). Figure S1 shows the major products found in the process liquid and the corresponding GC peaks. Furan compounds were not found, aside from the 2-methyl 3-furoic acid which was also detected in the trials that did not have added glucose. These would be expected in the degradation products of glucose, but were not found when glucose and $\beta$-estradiol were both degraded. The universally accepted HTC degradation mechanism of glucose must have interactions with either $\beta$-estradiol or its degradation products, as glucose was detected as a degradation product of the $\beta$-estradiol at all conditions while neither furfural nor hydroxymethyl furfural was found [34].

Ring opening, hydrolysis, and decarboxylation reactions are most likely responsible for the formation of the final products found in the product liquid. Figure 2 shows possible mechanisms for the formation of benzoic acid, 2-methyl 3-furoic acid, and 3-methyl butanoic acid from $\beta$-estradiol. Since these compounds are generated from the degradation of both investigated compounds, they are of particular interest. The proposed mechanism is based on Onwudili et al.'s similar mechanism for the formation of single ringed systems from polycyclic structures under hydrothermal conditions [35]. This degradation process follows the general path of decarbonylation of cyclic carbons followed by hydrolysis and decarboxylation of aliphatic carbons that result from ring opening reactions. Only products and direct results of these basics steps are shown, additional intermediates and side products that may still result in the major degradation products are not included. For maximizing the degradation of compounds similar to $\beta$-estradiol, hydrothermal processes at acidic conditions with an oxidizing agent are ideal, with longer treatment times at higher temperatures being secondary factors that enhance degradation. For processes that focus on breaking down all components found from the hydrothermal treatment of biologically hazardous compounds (and not just reducing the concentration of this $\beta$-estradiol specifically), targeting the most stable product or intermediate is the most important step. In this case, it is 


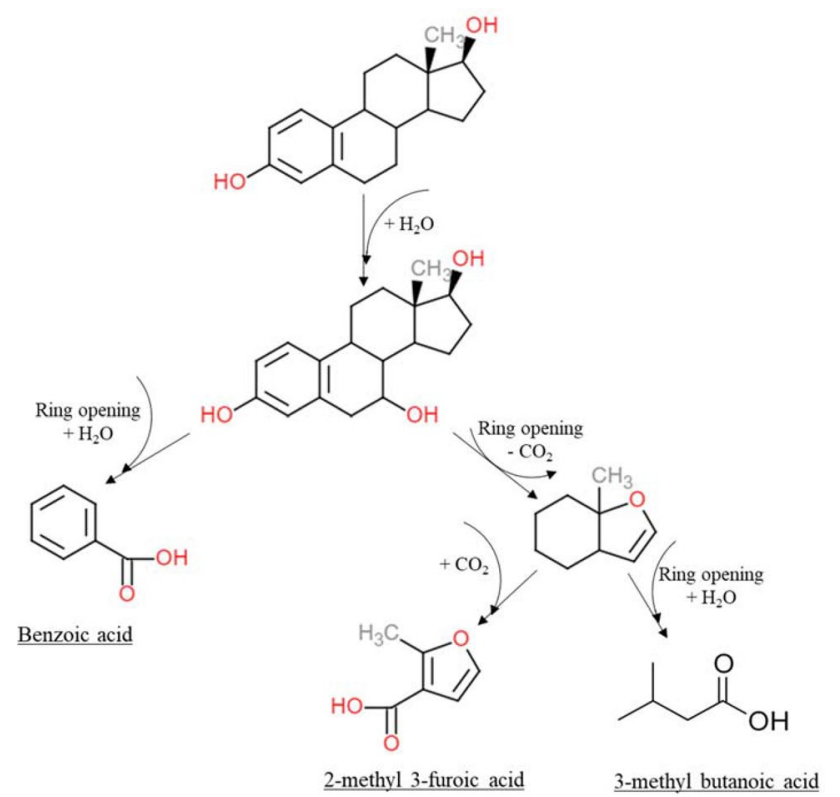

Figure. 2 Possible mechanism for the formation of benzoic acid, 2-methyl 3-furoic acid, and 3-methyl butanoic acid from $\beta$-estradiol

the benzoic acid found in the post-treatment liquid phase. This agrees with other studies that did not use catalysts or agents to target the benzoic acid or structurally similar compounds. Monocyclic aromatics with aliphatic acids have been detected in numerous studies evaluating the hydrothermal degradation of less homogenous feeds such as lignin, olive mill wastes, and dairy manure $[32,36,37]$.

\subsection{Degradation of oxytetracycline at different HTC conditions}

Oxytetracycline is a chemically unstable C6 hydroxyl group compound whose C-ring can be dehydrated and aromatized in the presence of acid [38]. The results from this study showed that oxytetracycline readily degraded to some extents at all HTC conditions, probably due to higher ionic products of water at subcritical conditions [39]. Initial analysis of the HPLC data suggested that the degradation of oxytetracycline was around $75 \%$ for all experimental conditions, with the exception of acidic and basic trials resulting in $81.6 \pm 1.1 \%$ and $84.1 \pm 2.9 \%$ degradation, respectively, as shown in Fig. 3 (both trials were for $0.5 \mathrm{~h}$ at $220^{\circ} \mathrm{C}$ ). However, the $25 \%$ remaining had a peak inconsistent with oxytetracycline, occurring sooner. This suggests that a larger ( $>300 \mathrm{~g} / \mathrm{mol}$ ) major degradation product is formed from the breaking down of the oxytetracycline. UV-Vis spectra revealed that the characteristic peak of oxytetracycline that appears around $350-370 \mathrm{~nm}$ was also completely absent. This product is most likely the major degradation product that is subsequently broken down into the smaller products. The acidic and basic trials only lowered the concentration of the major degradation product and did not change the secondary products formed, once again supporting an acid-/base-catalyzed ring opening-type reaction resulting in the formation of a benzoic acid compound. The addition of glucose did not have a significant impact on the degradation of the oxytetracycline, whereas with $\beta$-estradiol the presence of glucose severely enhanced the degradation. The difference is most likely due to degradation of these components. Glucose will degrade between 180 and $200^{\circ} \mathrm{C}$ [40], but by that point, oxytetracycline has already broken down into smaller components. With $\beta$-estradiol, glucose can interact with the degradation mechanism, but with oxytetracycline, glucose can only interact with the degradation products, as the initial degradation step has already been completed.

The degradation of oxytetracycline produces similar benzoic acid compounds (see Figure S2 and Table S2) to those found in the liquid product after $\beta$-estradiol degradation. The major degradation products, which were found at all hydrothermal conditions, include benzoic acid (78\% match), 2-methyl 3-furoic acid (79\% match),
Figure. 3 Percentage of degradation of oxytetracycline at different HTC conditions with and without the presence of glucose. The parent concentration of oxytetracycline was $13 \mathrm{mg} / \mathrm{L}$

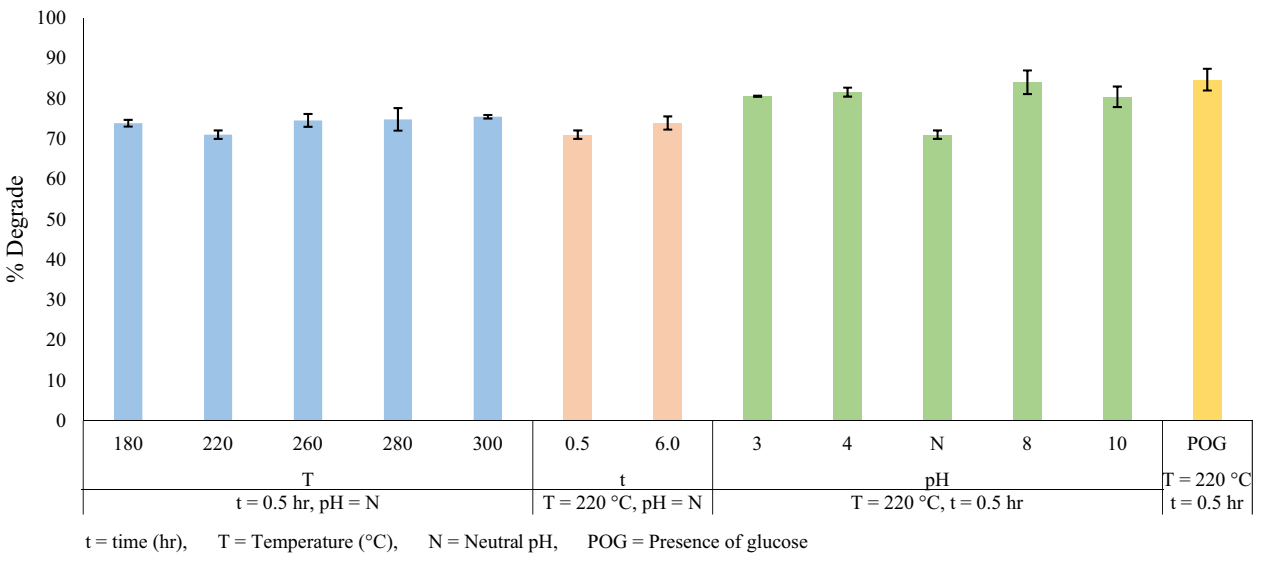

SN Applied Sciences 
3-phenyl-2-oxazolidinone ( $86 \%$ match), and 2,2 dimethyl butanol (59\% match). Previous work in hydrothermal degradation of nitrogen-containing aliphatic compounds has suggested a tautomerization-like mechanism that results in nitric or nitronic acid [41]. This mechanism may explain the formation of the only nitrogen-containing product (3-phenyl-2-oxazolidinone), where nitrogen is now part of a ring structure. This tautomerization mechanism would not only impact the nitrogen groups on oxytetracycline, but also the two enol locations. This nitrogen ring also explains why this fragment is so large compared to the results shown for $\beta$-estradiol, which had no nitrogen groups to form this type of ring. Tautomerization-like mechanisms involving hydrocarbons during hydrothermal treatment are well documented in producing valuable products like furfural [42]. Since tautomerization occurs so readily, it is expected that the degradation of oxytetracycline is rather complete or that at the very least significant changes in functionality occur. Figure 4 shows the possible mechanism for the formation of major products from the degradation of oxytetracycline. In addition to the decarbonylation and hydrolysis reactions proposed for $\beta$-estradiol, oxytetracycline must also experience additional ring opening and tautomerization reactions to produce these compounds. Both Kochansky et al. and Rose et al. observed significant degradation of oxytetracycline in water at atmospheric and hydrothermal conditions, respectively $[43,44]$, suggesting once again that the hydrothermal conditions are severe enough to achieve total degradation of oxytetracycline. Similar to the degradation of $\beta$-estradiol, more complete breakdown of the products requires the addition of an oxidizing agent to target the stable benzoic acid products that form from the aromatic ring.

\section{Conclusions}

Using a variety of hydrothermal treatment conditions, ranging from 180 to $300{ }^{\circ} \mathrm{C}, 0.5-6 \mathrm{~h}$, and $\mathrm{pH}$ 's of $3-10$; oxytetracycline and $\beta$-estradiol were degraded, and the degradation products were characterized. $\beta$-estradiol showed increased degradation with reaction severity with initial $\mathrm{pH}$ up to $100 \%$, with benzoic acid being the major degradation product. The addition of glucose greatly increased the degradation of $\beta$-estradiol, nearly eliminating it from the product liquid. Oxytetracycline was shown to be less stable than $\beta$-estradiol, with at least $71.0 \pm 1.1 \%$ degradation at all experimental conditions. Once again, the major degradation product was shown to be benzoic acid or some other functionalized monocyclic aromatic. Unlike $\beta$-estradiol, which had mostly smaller fragments (molecular mass $<150 \mathrm{~g} / \mathrm{mole}$ ) after treatment,

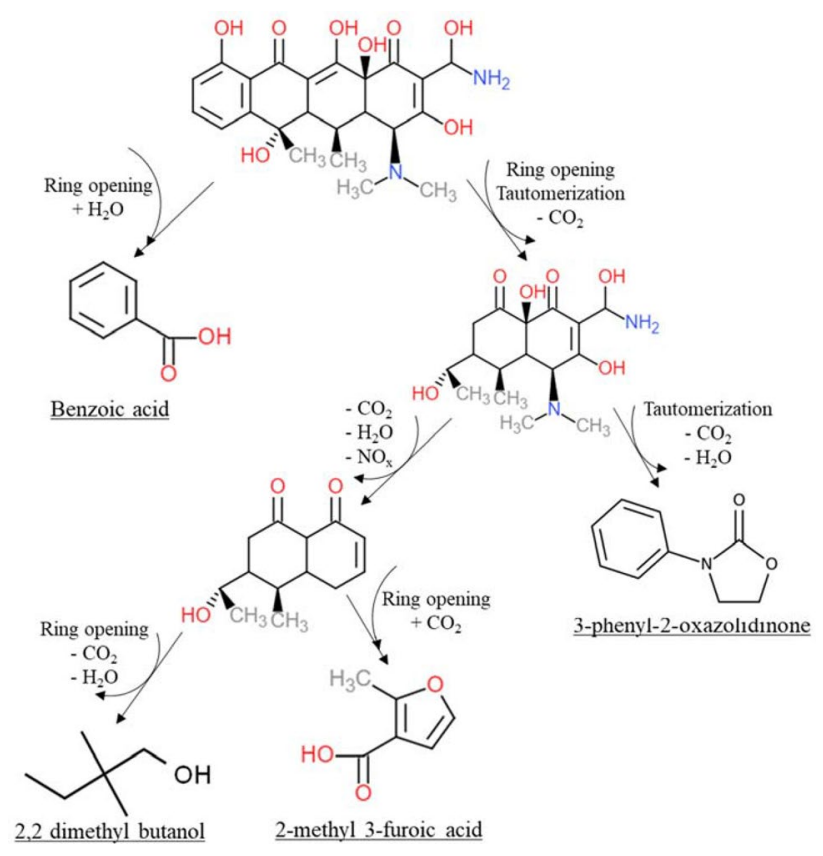

Figure. 4 Possible mechanism for the formation of benzoic acid, 2,2 dimethyl butanol, 2-methyl 3-furoic acid, and 3-phenyl-2-oxazolidinone from oxytetracycline

the hydrothermal degradation of oxytetracycline resulted in some larger fragments (molecular mass $>300$ ). Both the degradation of oxytetracycline and $\beta$-estradiol are most likely the result of acid- or base-catalyzed ring opening mechanisms. Hydrothermal degradation conditions that maximize the amount of either hydronium or hydroxide should be used when targeting these polycyclic structures by either increasing the adding acids or bases rather than simply increasing the treatment temperature.

Acknowledgements The research was funded by the US Department of Agriculture (USDA) grant (2019-67019-2928). The authors acknowledge Dr. Klaus Himmeldirk from the Chemistry Department at Ohio University for the use of GCMS. The authors are also thankful to Mr. Benjamin Vancouver at the Institute for Sustainable Energy and the Environment (ISEE) at Ohio University and Mr. John Elmore at Biochemistry Lab at Ohio University for their laboratory efforts in this project.

\section{Compliance with ethical standards}

Conflict of interest The authors declare that they have no competing interests.

\section{References}

1. Li F, Tang Y, Wang H, Yang J, Li S, Liu J, Tu H, Liao J, Yang Y, Liu $\mathrm{N}$ (2017) Functionalized hydrothermal carbon derived from waste pomelo peel as solid-phase extractant for the removal 
of uranyl from aqueous solution. Environ Sci Pollut Res 24(28):22321-22331

2. Borrero-López AM, Fierro V, Jeder A, Ouederni A, Masson E, Celzard A (2017) High added-value products from the hydrothermal carbonisation of olive stones. Environ Sci Pollut Res 24(11):9859-9869

3. Saha N, Saba A, Reza MT (2019) Effect of hydrothermal carbonization temperature on $\mathrm{pH}$, dissociation constants, and acidic functional groups on hydrochar from cellulose and wood. J Anal Appl Pyrol 137:138-145

4. Ramesh S, Sundararaju P, Banu KSP, Karthikeyan S, Doraiswamy $U$, Soundarapandian K (2019) Hydrothermal carbonization of arecanut husk biomass: fuel properties and sorption of metals. Environ Sci Pollut Res 26(4):3751-3761

5. Hoekman SK, Broch A, Robbins C (2011) Hydrothermal carbonization (HTC) of lignocellulosic Biomass. Energy Fuels 25(4):1802-1810

6. Hu B, Wang K, Wu L, Yu S-H, Antonietti M, Titirici M-M (2010) Engineering carbon materials from the hydrothermal carbonization process of biomass. Adv Mater 22(7):813-828

7. Sevilla M, Fuertes AB (2009) Chemical and structural properties of carbonaceous products obtained by hydrothermal carbonization of saccharides. Chem Eur J 15(16):4195-4203

8. Saha N, Saba A, Saha P, McGaughy K, Franqui-Villanueva D, Orts JW, Hart-Cooper MW, Reza TM (2019) Hydrothermal carbonization of various paper mill sludges: an observation of solid fuel properties. Energies 12(5):858

9. Song C, Shan S, Müller K, Wu S, Niazi NK, Xu S, Shen Y, Rinklebe J, Liu D, Wang $\mathrm{H}$ (2018) Characterization of pig manure-derived hydrochars for their potential application as fertilizer. Environ Sci Pollut Res 25(26):25772-25779

10. Kasiuliene A, Carabante I, Bhattacharya P, Kumpiene J (2019) Hydrothermal carbonisation of peat-based spent sorbents loaded with metal(loid)s. Environ Sci Pollut Res 26(23):23730-23738

11. Kolpin DW, Furlong ET, Meyer MT, Thurman EM, Zaugg SD, Barber LB, Buxton HT (2002) pharmaceuticals, hormones, and other organic wastewater contaminants in us streams, 1999-2000: a national reconnaissance. Environ Sci Technol 36(6):1202-1211

12. Soto Ana M, Calabro Janine M, Prechtl Nancy V, Yau Alice $Y$, Orlando Edward F, Daxenberger A, Kolok Alan S, Guillette Louis J, le Bizec B, Lange Iris G, Sonnenschein C (2004) Androgenic and estrogenic activity in water bodies receiving cattle feedlot effluent in Eastern Nebraska USA. Environ Health Perspect 112(3):346-352

13. Bird K, Boopathy R, Nathaniel R, LaFleur G (2019) Water pollution and observation of acquired antibiotic resistance in Bayou Lafourche, a major drinking water source in Southeast Louisiana. Environmental Science and Pollution Research, USA

14. Xue $Y$, Gao B, Yao Y, Inyang $M$, Zhang $M$, Zimmerman AR, Ro KS (2012) Hydrogen peroxide modification enhances the ability of biochar (hydrochar) produced from hydrothermal carbonization of peanut hull to remove aqueous heavy metals: batch and column tests. Chem Eng J 200:673-680

15. Chen J, Zhang L, Yang G, Wang Q, Li R, Lucia LA (2017) Preparation and characterization of activated carbon from hydrochar by phosphoric acid activation and its adsorption performance in prehydrolysis liquor. BioResources 12(3):5928-5941

16. Möller M, Nilges $P$, Harnisch F, Schröder U (2011) Subcritical water as reaction environment: fundamentals of hydrothermal biomass transformation. Chemsuschem 4(5):566-579

17. Bandura AV, Lvov SN (2005) The ionization constant of water over wide ranges of temperature and density. J Phys Chem Ref Data 35(1):15-30

18. Danso-Boateng E, Holdich RG, Shama G, Wheatley AD, Sohail M, Martin SJ (2013) Kinetics of faecal biomass hydrothermal carbonisation for hydrochar production. Appl Energy 111:351-357

19. Weiner B, Baskyr I, Poerschmann J, Kopinke F-D (2013) Potential of the hydrothermal carbonization process for the degradation of organic pollutants. Chemosphere 92(6):674-680

20. vom Eyser C, Palmu K, Schmidt TC, Tuerk J (2015) Pharmaceutical load in sewage sludge and biochar produced by hydrothermal carbonization. Sci Total Environ 537:180-186

21. Shin YH, Schideman L, Plewa MJ, Zhang P, Scott J, Zhang Y (2019) Fate and transport of estrogenic compounds in an integrated swine manure treatment systems combining algal-bacterial bioreactor and hydrothermal processes for improved water quality. Environ Sci Pollut Res 26(16):16800-16813

22. Gong P, Liu H, Wang M, Dai X, Yao J (2020) Characteristics of hydrothermal treatment for the disintegration of oxytetracycline fermentation residue and inactivation of residual antibiotics. Chem Eng J 402:126011

23. Alavi N, Babaei AA, Shirmardi M, Naimabadi A, Goudarzi G (2015) Assessment of oxytetracycline and tetracycline antibiotics in manure samples in different cities of Khuzestan Province Iran. Environ Sci Pollut Res 22(22):17948-17954

24. Raman DR, Layton AC, Moody LB, Easter JP, Sayler GS, Burns RT, Mullen MD (2001) Degradation of estrogens in dairy waste solids: effects of acidification and temperature. T Asae 44(6):1881-1888

25. FDA, Code of Federal Regulations (CFR), Title 21, Parts 522 and 556, 2016.

26. Ray P, Zhao Z, Knowlton KF (2013) Emerging contaminants in livestock manure: hormones, antibiotics and antibiotic resistance genes. In: Kebreab E (ed) Sustainable animal agriculture. $\mathrm{CABI}$, Boston

27. Yalkowsky SH, Dannenfelser RM (1992) The aquasol database of aqueous solubility. College of Pharmacy, University of Arizona, Tucson, $A Z$

28. McCollom TM, Seewald JS, Simoneit BRT (2001) Reactivity of monocyclic aromatic compounds under hydrothermal conditions. Geochim Cosmochim Acta 65(3):455-468

29. Katritzky AR, Balasubramanian M, Siskin M (1990) Aqueous hightemperature chemistry of carbo- and heterocycles 2 monosubstituted benzenes: benzyl alcohol, benzaldehyde and benzoic acid. Energy Fuels 4(5):499-505

30. Quitain AT, Faisal M, Kang K, Daimon H, Fujie K (2002) Lowmolecular-weight carboxylic acids produced from hydrothermal treatment of organic wastes. J Hazard Mater 93(2):209-220

31. Gao Y, Wang X-H, Yang H-P, Chen H-P (2012) Characterization of products from hydrothermal treatments of cellulose. Energy 42(1):457-465

32. Onwudili JA, Williams PT (2007) Reaction mechanisms for the decomposition of phenanthrene and naphthalene under hydrothermal conditions. J Supercrit Fluids 39(3):399-408

33. Reza MT, Wirth B, Luder U, Werner M (2014) Behavior of selected hydrolyzed and dehydrated products during hydrothermal carbonization of biomass. Biores Technol 169:352-361

34. Promdej C, Matsumura $Y$ (2011) Temperature effect on hydrothermal decomposition of glucose in sub- and supercritical water. Ind Eng Chem Res 50(14):8492-8497

35. Onwudili JA, Williams PT (2007) Reaction mechanisms for the hydrothermal oxidation of petroleum derived aromatic and aliphatic hydrocarbons. J Supercrit Fluids 43(1):81-90

36. Poerschmann J, Baskyr I, Weiner B, Koehler R, Wedwitschka H, Kopinke FD (2013) Hydrothermal carbonization of olive mill wastewater. Biores Technol 133:581-588

37. Theegala CS, Midgett JS (2012) Hydrothermal liquefaction of separated dairy manure for production of bio-oils with simultaneous waste treatment. Biores Technol 107:456-463 
38. Pines H, Pillai CN (1960) Dehydration of alcohols over alumina modified by ammonia1,2. J Am Chem Soc 82(9):2401-2402

39. Kruse A, Dahmen N (2015) Water - a magic solvent for biomass conversion. J Supercrit Fluids 96:36-45

40. Reza MT, Nover J, Wirth B, Coronella CJ (2016) Hydrothermal carbonization of glucose in saline solution: sequestration of nutrients on carbonaceous materials. Aims Energy 4(1):173-189

41. Iyer SD, Nicol GR, Klein MT (1996) Hydrothermal reactions of 1-nitrobutane in high-temperature water. J Supercrit Fluids 9(1):26-32

42. Jin F, Enomoto H (2011) Rapid and highly selective conversion of biomass into value-added products in hydrothermal conditions: chemistry of acid/base-catalysed and oxidation reactions. Energy Environ Sci 4(2):382-397
43. Kochansky J, Knox D, Shimanuki H (1999) Comparative stability of oxytetracycline and tylosin in sugar syrup. Apidologie 30(4):321-326

44. Rose MD, Bygrave J, Farrington WHH, Shearer G (1996) The effect of cooking on veterinary drug residues in food: 4 Oxytetracycline. Food Addit Contam 13(3):275-286

Publisher's Note Springer Nature remains neutral with regard to jurisdictional claims in published maps and institutional affiliations. 